\title{
MODELING THERMAL STRAIN OF CONCRETE AT MESOSCALE
}

\author{
JOSIPA BOŠNJAK ${ }^{*}$, JOŠKO OŽBOLT ${ }^{\dagger}$ \\ "University of Stuttgart \\ Stuttgart, Germany \\ e-mail: josipa.bosnjak@mpa.uni-stuttgart.de \\ ${ }^{\dagger}$ University of Stuttgart \\ Stuttgart, Germany \\ e-mail: ozbolt@iwb.uni-stuttgart.de
}

Key words: Concrete, High temperature, Thermal strains, Mesoscale modeling approach

\begin{abstract}
As heterogeneous material, concrete exhibits very complex behavior when exposed to elevated temperature. One of the important aspects is the load-induced thermal strain (LITS), which represents the difference between the thermal strain of non-loaded and loaded concrete. Even though a great amount of research has been performed so far, there is still no general consensus about the mechanism that leads to the change of thermal behavior when concrete is loaded in compression prior to heating. In the present paper, the thermal behavior of concrete is analyzed employing 3D finite element code with temperature dependent microplane model as a material constitutive law. Concrete is modeled at mesoscale, whereby two cases are considered: (i) concrete as a composite of concrete mortar and aggregates and (ii) concrete as a composite of cement paste and aggregates. The approach is validated against experiments available from the literature. It is shown that the heterogeneous structure of concrete plays a crucial role in damage processes at elevated temperature and hence has a major influence on the thermal strain of loaded concrete.
\end{abstract}

\section{INTRODUCTION}

Understanding the response of concrete and reinforced concrete structures at elevated temperature is essential for assuring reliable fire design. Exposure to elevated temperature causes degradation of mechanical and physical properties of concrete, as a result of incompatibility between the material phases and degradation of individual phases, cement paste and aggregates. Furthermore, the phase change of water available in the porous system at around $100^{\circ} \mathrm{C}$ also influences the behavior.

The complex thermal strain of concrete represents a very important parameter for understanding the material behavior as well as its consequences on the structural level. As the majority of engineering materials, concrete expands when exposed to a temperature increase and this strain is termed "free thermal strain", since it measured on specimens free to expand (load free specimens). The individual concrete constituents exhibit very different behavior with respect to the thermal expansion. Aggregates expand almost linearly with increasing temperature; the magnitude of the expansion depends on the aggregate composition and properties. Cement paste, on the other hand, expands only up to approximately 120 $200^{\circ} \mathrm{C}$, hereafter it contracts. The thermal strain of cement paste is strongly influenced by the evaporation of water in the temperature range close to the boiling point of water. Hence, for lower heating rates cement paste starts to contract at lower temperatures, since 
more time is available for the evaporation process. Overall free thermal strain of concrete is positive. Even if one considers only mortar as a combination of cement paste and fine aggregates, the total deformation is positive throughout the heating range. This is attributed to the relatively large volumetric ratio of sand and coarse aggregates in concrete. Hager [1] showed that up to $400^{\circ} \mathrm{C}$ free thermal strain of concrete is almost completely reversible upon subsequent cooling, which can be attributed primarily to the relatively low incompatibility of the thermal strain between the concrete constituents, and partially to the moderate degree of damage in the cement paste and aggregates. At higher temperatures $\left(600^{\circ} \mathrm{C}\right)$ free thermal strain is only partially reversible, since the damage due to the increased thermal incompatibility progressively increases and the (irreversible) degradation takes place in all concrete constituents.

When concrete is initially loaded in compression and subsequently heated, the overall thermal strain deviates from the free thermal strain curve (see Figure 1). The expansion is in general reduced with respect to the free thermal strain.

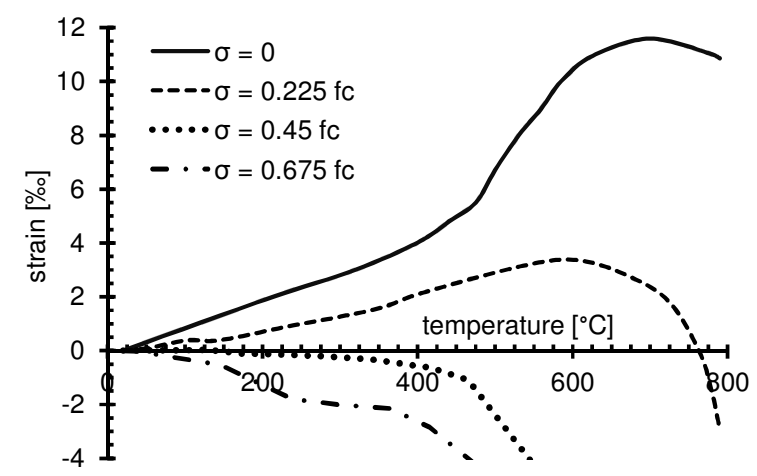

Figure 1. Thermal strain of the concrete [2]

Upon further temperature increase the expansion can change to contraction, finally leading to a failure in compression. The difference between the free thermal strain and thermal strain of loaded concrete is known as loadinduced thermal strain (LITS) or thermal creep, see Figure 2. However, the latter expression is not quite appropriate, since this strain is not time dependent in a strict sense, as the term creep indicates.

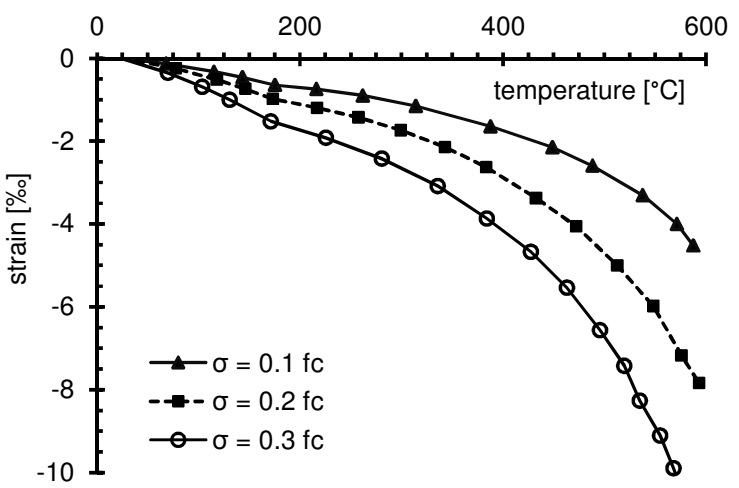

Figure 2. LITS master curve acc. to Khoury [3]

In general, it is found that LITS depends strongly on the level of the applied compressive stress. Unlike free thermal strain, LITS is not reversible upon cooling and occurs only during the initial heating. The effect of the compressive stress on thermal strain was first observed in the 1960-ies and has been vastly investigated since [1,2,4-7]. Khoury [3-5] performed several experimental studies, where most of the relevant parameters such as load level, aggregate type, degree of saturation etc. were varied. He postulated that the drying processes in the C-S-H structure govern LITS, at least up to $450^{\circ} \mathrm{C}$. More recent studies performed by Hager et al. [1] demonstrated, however, that the drying processes in the cement paste are only partially responsible for the observed behavior. The authors investigated the behavior of aggregates, cement paste and concrete and measured both axial and radial thermal strain. Based on the presented results, it was concluded that up to temperature of 300 $400^{\circ} \mathrm{C}$ LITS of concrete is caused mainly by drying of cement paste (drying creep and so called dehydration creep [8]). Beyond this temperature the thermal strain is governed by the cracking processes induced by the thermal incompatibility of the cement paste and aggregates.

The most of the numerical models for concrete follow the simplified approach for LITS by defining it explicitly for the use at the macroscale. These models are developed on the basis of experimental results, see for example [9-12]. The 3D finite element code [13], used 
in this study, also employs the model proposed by Nielsen et al. $[10,14]$ for macroscopic modeling of concrete. It has been shown that this model is capable of capturing the experimental results. Such approach is practical for structural applications; however, it does not offer insight into the underlying mechanism. Further work is also required to assure the applicability of such models outside the range of the performed experiments, i.e. on the structural level, especially for the members loaded in compression, influence of high levels of restraint and the influence of duration of loading at high temperature. The current codes and guidelines such as Eurocode 2 [15] favor an implicit approach to consider the thermal strain of concrete, whereby no distinction is made between heating in non-loaded and loaded conditions.

Several authors have performed numerical analysis at mesoscale to simulate the thermal strain of concrete, whereby LITS were not included in the numerical model in a phenomenological manner. The first study which underlined the advantages of this approach was performed by Willam et al [16]. Grondin et al. [17] obtained a qualitatively good match with the experimental data when performing mesoscale analysis for elastic materials. Based on the analysis at mesoscale Mounajed et al. [18] concluded that LITS originates from the material degradation at elevated temperatures. Grassl and Pierce [19] employed a plasticity constitutive model in the framework of the lattice modeling domain and demonstrated that the LITS originates principally from the incompatibility of the concrete phases. Even though the studies have been performed considering simple two-dimensional geometries, a relatively good agreement with the experimental data has been observed.

\section{RESEARCH SIGNIFICANCE}

Understanding the thermal behavior of concrete is of great importance for the design and analysis of the reinforced concrete structures. LITS plays a crucial role in the overall concrete thermal strain, since it can significantly influence the stress relaxation and redistribu- tion. Many experimental studies have confirmed the existence of LITS for various types of concrete and individual constituents (cement, aggregates etc.), and identified some of the influencing parameters. Nevertheless, there is still no generally accepted explanation of the underlying mechanism. The complexity of the testing at elevated temperatures limits the range of parameters, which can be directly measured or monitored during the test. Numerical analysis, on the other hand, can provide useful information and offer explanation to several important questions, such as the irreversibility of the LITS upon subsequent cooling and the difference in the failure mode in case of non-loaded and loaded concrete exposed to heating. The majority of the existing macroscopic numerical approach is phenomenological and based on the experimental results obtained on small specimens, thus possibly limiting its applicability. In addition, this approach does not provide the much needed understanding of the mechanics behind the phenomena. The work performed so far employing mesoscale modeling approach showed significant improvements in the understanding of the LITS origin.

In the present numerical study it is attempted to clarify the contribution of the thermal strain of the individual constituents to the thermal strain of mortar (consisting of the cement paste and sand) and concrete (consisting of the mortar and coarse aggregates) in case of non-loaded and loaded specimen. The numerical analysis is aimed at providing more insight into the behavior and causes of LITS. In order to achieve this it is necessary to consider the concrete at mesoscale instead of the typically used macroscale modeling approach. In this work, a full three-dimensional model is used in the numerical analysis, in comparison to the previous work which mainly dealt with more simple two-dimensional models.

\section{NUMERICAL ANALYSIS}

\subsection{Thermo-mechanical model for concrete}

In the present work a thermo-mechanical model based on the temperature dependent 
microplane model as the constitutive law for concrete is employed [20,21]. This model has been vastly validated against various experiments [22-24].

In the microplane model, the material is characterized by the relation between the stress and strain components on planes of various orientations. These planes may be imagined to represent the damage or weak planes in the microstructure, such as those that exist at the contact between aggregate and cement matrix. In the model, the tensorial invariance restrictions do not need to be directly enforced, since these are automatically satisfied by superimposing the responses from all microplanes in a suitable manner. Damage and cracking are modeled in the framework of the smeared crack continuum. To assure objectivity of the analysis with respect to the size of the finite elements crack band method is used [25]. The microplane model used in this work was proposed by Ožbolt et al. [26].

The temperature dependency of the microplane model is adopted such that the macroscopic properties of concrete (Young's modulus, compressive and tensile strength and fracture energy) are temperature dependent $[27,28]$. In a given time step during the incremental nonlinear finite element analysis, the material parameters, as well as the temperature distribution, are assumed to be constant. For more detail see [20,21].

As the first step of coupling between mechanical properties of concrete and temperature, the temperature distribution over a solid structure of volume at a given time is calculated by fulfilling the energy conservation law.

The total strain tensor for stressed concrete exposed to high temperature can be decomposed into mechanical strain, free thermal strain and load-induced thermal strain. In general, the mechanical strain component can be decomposed into elastic, plastic and damage part. These strain components are obtained from the constitutive law. The free thermal strain is stress independent and is experimentally obtained by measurements on the unloaded specimen. The load-induced thermal strain is stress and temperature dependent $[10,21]$. As mentioned above, the present thermo- mechanical model imposes LITS directly in case when concrete is considered as a homogeneous material, i.e. at macroscale level. However, it is assumed that such approach is not valid when analyzing concrete at mesoscale level (concrete as a heterogeneous material consisting of cement mortar or paste and aggregates). It is presumed that the majority of the load-induced thermal strain originates from the incompatibility of the aggregates and mortar (or cement paste) and should, as such, be a part of the model response.

Hence, the load-induced thermal strains were not imposed on either of the concrete constituents when considering concrete at mesoscale. The only thermal strain imposed directly is the free thermal strain for each of the concrete constituents. The validity of these assumptions has been investigated by analyzing an experiment available from the literature. The numerical modeling approach and the results are discussed in the following section.

\subsection{Modeling load induced thermal strain}

The numerical analysis was performed by simulating the experiments reported by Hager [1]. Concrete cylinders with diameter of 104 $\mathrm{mm}$ and height of $300 \mathrm{~mm}$ were loaded to various compressive stress levels $(0 \%, 20 \%$ and $40 \%$ of the virgin compressive strength) at room temperature and subsequently heated up to $600^{\circ} \mathrm{C}$ or until failure. The specimens were heated slowly at approximately $1{ }^{\circ} \mathrm{C} / \mathrm{min}$, in order to avoid high thermal gradients within the specimen. The experiments were performed on several types of concrete ranging from ordinary to high performance concrete. In the present work, only concrete class M30 is considered. The corresponding material properties are summarized in Table 1 .

In the numerical study concrete was discretized as a mixture of two phases and two cases were considered:

a) Concrete as a composite of cement paste and aggregates with a volumetric ratio of aggregates in concrete of ca. $70 \%$

b) Concrete as a composite of cement mortar and coarse aggregates with a volumetric ratio of aggregates of ca. $22 \%$ 
The finite element discretization for the two models is shown in Figure 3.

Table 1. Material properties used in the analysis

\begin{tabular}{cccc}
$\begin{array}{c}\text { Material } \\
\text { property }\end{array}$ & Mortar & Aggregates & $\begin{array}{c}\text { Cement } \\
\text { paste }\end{array}$ \\
\hline$f_{c, c y l}[\mathrm{MPa}]$ & 37.0 & - & 37.0 \\
\hline$G_{f}[\mathrm{~N} / \mathrm{mm}]$ & 0.08 & - & 0.08 \\
\hline$E[\mathrm{MPa}]$ & 32000 & 60000 & 32000 \\
\hline$f_{t}[\mathrm{MPa}]$ & 3.20 & - & 3.20
\end{tabular}

a)

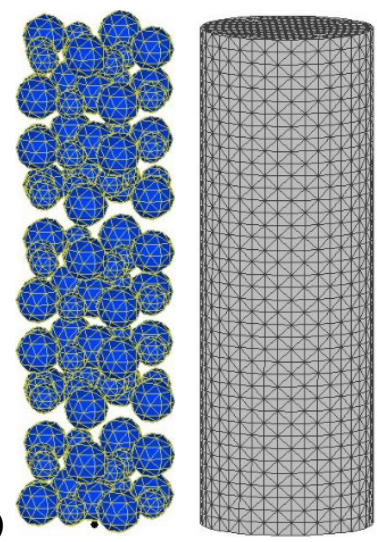

b)

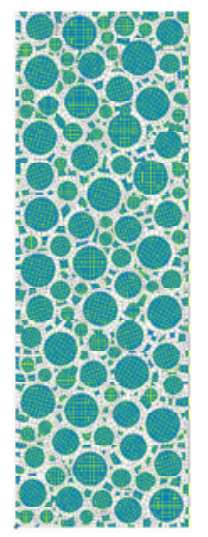

Figure 3. Finite element model of concrete: volumetric ratio of aggregates ca. $22 \%$ (a) and $70 \%$ (b)

\subsubsection{Concrete as a composite of cement paste and aggregates}

In the first case, concrete consisted of coarse and fine aggregates embedded in the cement paste, with a total volumetric ratio of aggregates of approximately $70 \%$, see Figure 3 . Due to the high modeling and computational demand in case of such detailed model, a simplified case was considered (aggregates size ranged from $2 \mathrm{~mm}$ to $20 \mathrm{~mm}$ ). The finite element discretization was three-dimensional, but only one slice of the specimen was modeled. The analysis was performed under assumption of plane stress state. The material properties for the cement paste and aggregates are summarized in Table 1. Two cases were considered with respect to the thermal strain of cement:

a) Cement paste expands up to $180^{\circ} \mathrm{C}$, thereafter it shrinks

b) Cement paste experiences no thermal strain up to $200^{\circ} \mathrm{C}$, thereafter it shrinks.
The corresponding free thermal strains for the two analyses are provided in Figure 4. The analysis (a) simulates the realistic case observed in the experiment. The analysis (b) aims at eliminating the influence of the cement paste expansion on the behavior. These two analyses can provide more understanding regarding the contribution of the drying processes on LITS, since the initial expansion of the cement paste is primarily associated with the water evaporation in the cement paste.

The results of the analysis and the corresponding experimental data are presented in Figure 5. The results are presented in terms of the master LITS curve. It can be observed that the numerical model realistically reflects the results of the experimental measurements, particularly if one considers the relative simplicity of the modeling approach. With increasing load level and temperature, the effect of the load on the total thermal strain becomes more pronounced.

It is apparent that the analysis (b) gives better agreement with the experiment. Analysis (a) shows no LITS up to approximately $200^{\circ} \mathrm{C}$, i.e. up to the temperature level where the thermal strain of the aggregate becomes higher than that of the cement paste. These results clearly show that the drying processes in the cement paste influence the thermal strain in the temperature range up to $200^{\circ} \mathrm{C}$, or more precisely, in the range of expansion of cement paste. However, it should be noted that the overall LITS in this range is rather small compared to the effect at higher temperatures. Beyond $200^{\circ} \mathrm{C}$ the difference in the free thermal strain of the concrete components assumes the governing role.

Damage patterns for the non-loaded and loaded specimen are shown in Figure 6. In general, the damage is similar to that observed in the experiment. In case of the non-loaded specimen, the material is free to expand in all direction resulting in a random crack pattern. With the increasing level of compressive stress (applied prior to heating), the axial strain decreases, and after certain temperature the specimen fails in compression. Since the axial expansion of the specimen is partially restrained, the material expands more in the radial direc- 
tion. This leads to cracking parallel to the loading direction. These cracks are more localized than those in case of the free thermal strain and are wider. This type of damage caused by the presence of the compressive load before the heating can partially explain the irreversible nature of LITS.

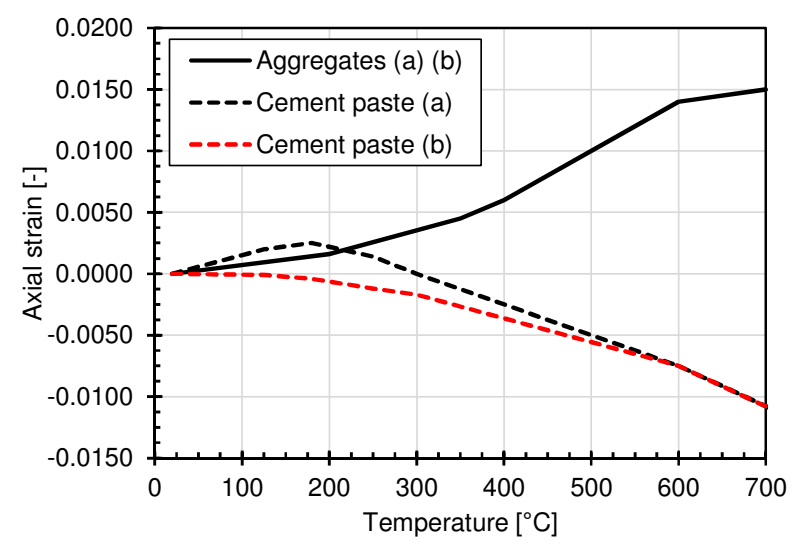

Figure 4. Free thermal strain of the concrete phases

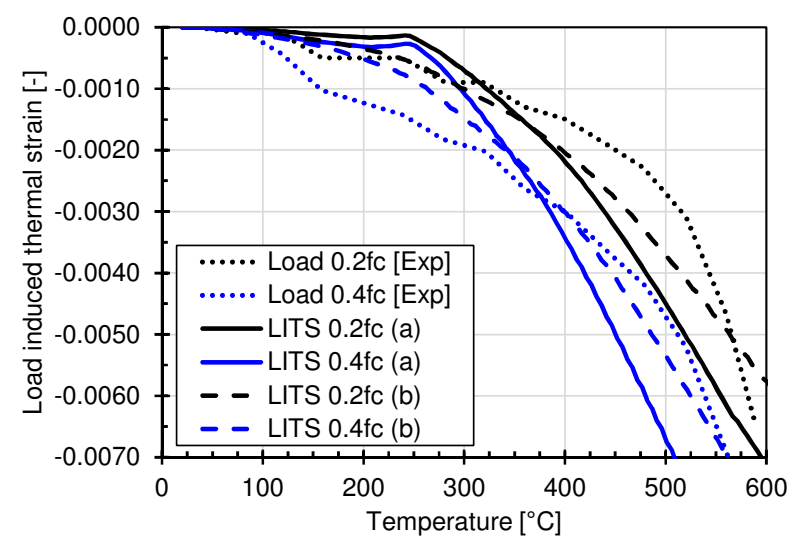

Figure 5. Comparison of the numerical and experimental results for the analyzed cases (a) and (b)

The presented results demonstrate that thermal strain can be realistically predicted if mesoscale modeling approach is followed. In this case there is no need for the explicit definition of LITS in the numerical model. The vast part of LITS strain is a consequence of the thermal incompatibility of the concrete phases, particularly at higher temperature. At lower temperatures the presence of water reflected in the drying processes at cement paste governs the behavior. The present thermo-mechanical model does not explicitly account for these drying processes, however, the total thermal strain can be realistically predicted. The results are significantly closer to the experimental data if the expansion cement paste is neglected. Predicting the initial LITS in the lower temperature range is of particular importance for fully restrained material.
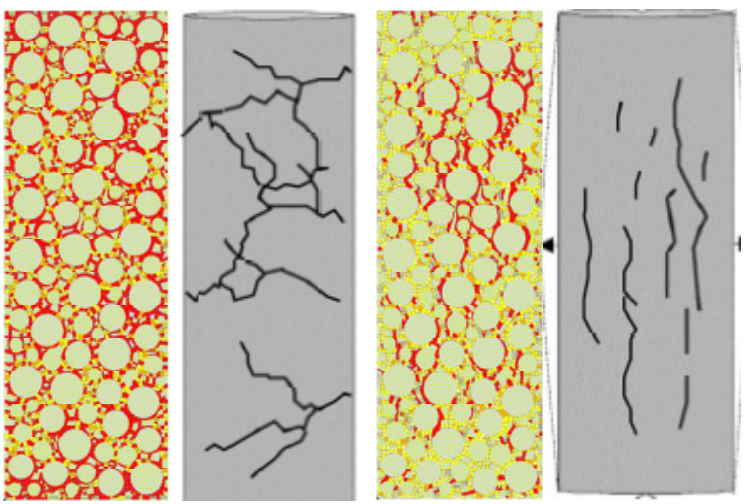

Figure 6. Comparison of the numerically obtained crack patterns with those from the experiment [1] for the non-loaded (a) and loaded specimen (b)

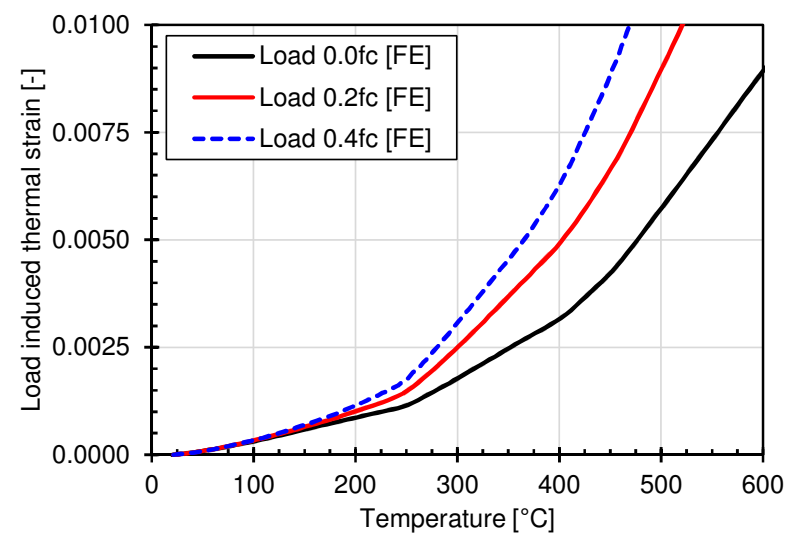

Figure 7. Radial thermal strain in the mid-height of the specimen (FE analysis)

\subsubsection{Concrete as a composite of mortar and aggregates}

In the second model concrete was discretized as a two-phase material consisting of cement mortar and spherical coarse aggregates. This simplified approach is often preferred to more complex models. The aim of the present study is to investigate whether such a simplified model is capable of realistically capturing the thermal behavior of concrete.

The total ratio of the aggregates in concrete was approximately $22 \%$ by volume. In the numerical analysis only three aggregate sizes $(10,14$ and $24 \mathrm{~mm})$ were considered. It is recognized that the inclusion of the interfacial transition zone (ITZ) between the aggregates 
and cement mortar would improve the consistency; however, this aspect was omitted due to the increased computational demand associated with introduction of ITZ into the 3D model. Nevertheless, this simplification should not influence the general trends in thermal strain nor crack patterns.

The mechanical properties of concrete and its constituents as reported in [1] are used in the numerical analysis, see Table 1. The material properties not provided in [1] are assumed using the literature data. The free thermal strain is assumed to be linear with expansion coefficients for mortar and aggregates are assumed to be $10^{-5} \mathrm{~K}^{-1}$ and $1.70 \times 10^{-5} \mathrm{~K}^{-1}$, respectively.

The comparison between numerical and experiment results is shown in Figure 8 as the total axial strain vs. temperature. In Figure 9 the master LITS curves for the same model is shown. In general, the numerical results reproduce the experimentally observed behavior very well. Similarly as in the previous case, the loading prior to heating leads to reduced strain in the axial and increased strain in the radial direction. The development of radial strain with temperature shown in Figure 10 is similar to that shown in Figure 7.

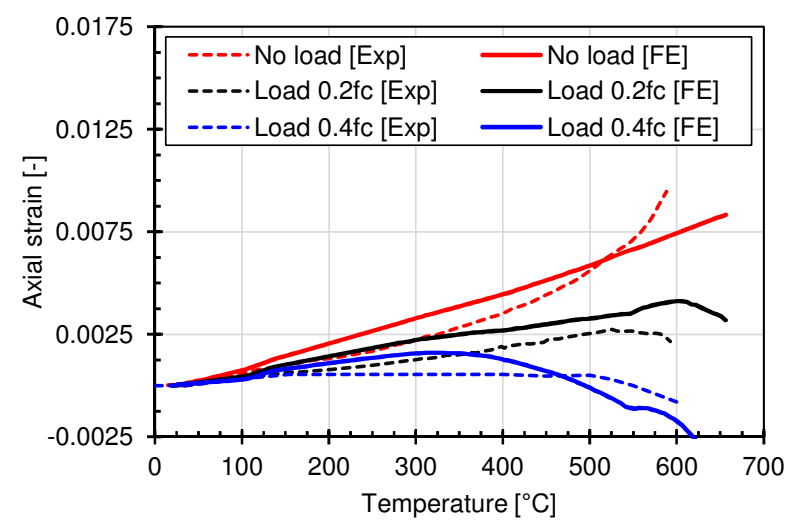

Figure 8. Total axial thermal strain of the concrete under different stress levels - comparison of the numerical results with the experimental data from [1]

Failure modes (crack patterns) for the nonloaded and loaded specimens are shown in Figure 11. Load-free specimen tends to expand uniformly in all directions, which results in a random cracking pattern. Specimen loaded in compression deforms less in the axial and more in the radial direction than the nonloaded specimen, which is reflected in the crack pattern with cracks running parallel to the loading direction. Due to the incompatibility of the thermal strain between the concrete phases (here aggregates and cement mortar) cracks develop in the cement mortar and ITZ. These cracks interact with the load induced damage of concrete.

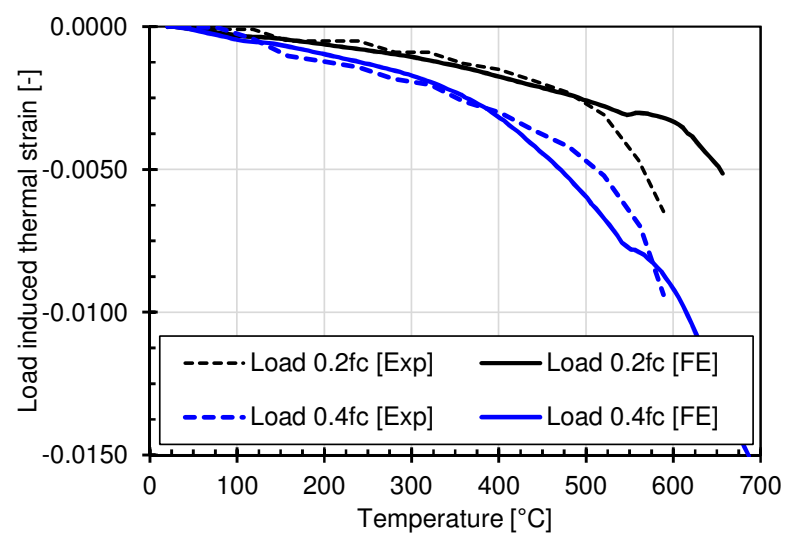

Figure 9. Master LITS curve - comparison of the numerical results (a) with the experimental data [1]

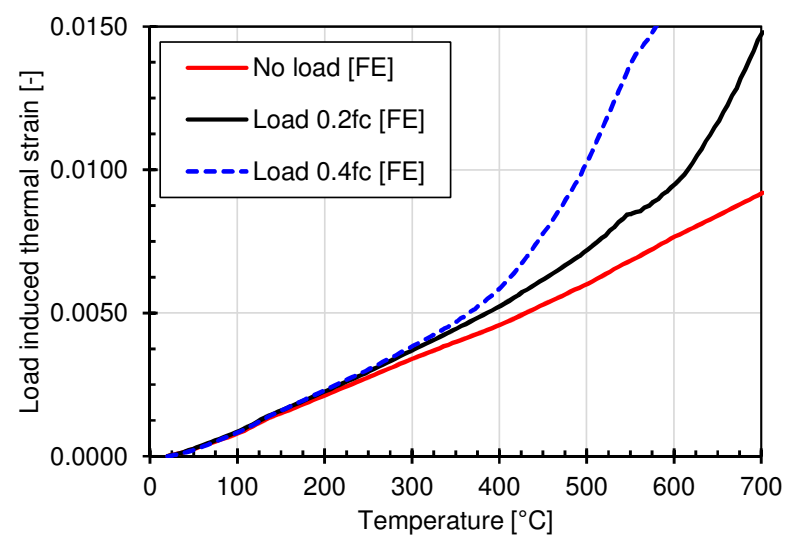

Figure 10. Radial strain in the mid-height (FE analysis)

Consequently, the load-transfer mechanism in concrete changes, i.e. the load tends to be transferred more through mortar and less through aggregate, which leads to LITS because damaged mortar or cement paste is much weaker than the aggregate. Even though the present model is quite a crude representation of the concrete structure with only ca. $22 \%$ of aggregates per volume of concrete, it provides realistic results.

If concrete is discretized considering only the ratio of the coarse aggregates, the free thermal strain for the matrix should be as- 
sumed to correspond to those of the cement mortar (positive strain throughout the heating phase). However, if more realistic ratio of the aggregates is included in the model, the matrix should reflect the thermal behavior typical for cement paste.

a)
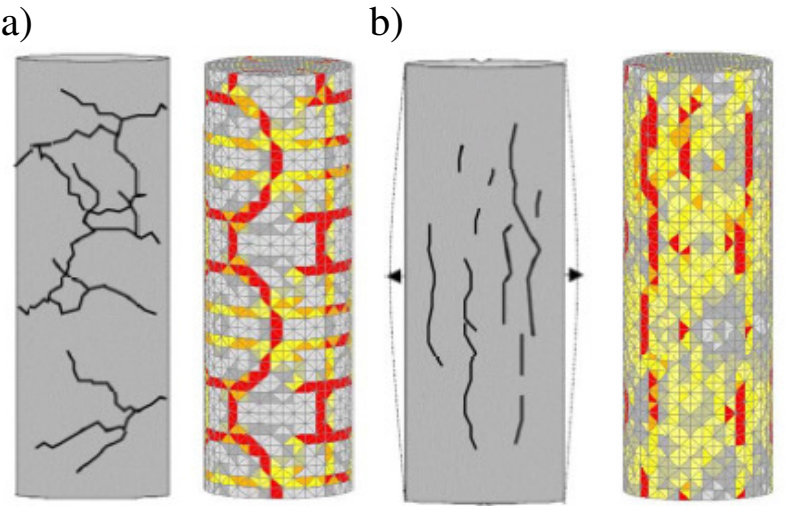

Figure 11. Comparison of the numerically obtained crack patterns with those from the experiment [1] for the non-loaded (a) and loaded specimen (b)

A number of researchers concluded that the load-induced thermal strain is present only upon the initial heating, that it is irreversible and absent upon repeated heating of concrete. The irreversible nature at lower temperatures can be explained by the drying processes in cement paste, which are generally irreversible. It is important to note that the thermal strain of cement paste (initial expanding portion) is greatly influenced by the heating rate, as shown by Hager [1]. Hence, the water movement and evaporation occurs at lower temperatures for lower heating rates, and later for higher heating rates. This aspect is particularly relevant when considering higher rates of heating with phenomena such as pore pressure build up.

Beyond approximately $200^{\circ} \mathrm{C}$ the behavior seems to be at least partially governed by the strain incompatibility. The degree of this influence is dependent on the degree of thermal incompatibility of the aggregates and mortar, which is increasing with rising temperatures.

\section{CONCLUSIONS}

In the present work the thermal strain of concrete was investigated based on the numerical simulation at mesoscale. Concrete has been discretized as a composite of cement mortar and coarse aggregates. The numerical approach was validated against two experiments available from the literature [1,2,29]. Based on the results present above, following can be concluded: (1) Macroscale modeling approach can be used to simulate LITS only if these are directly imposed at the material level (explicit definition of LITS), however, such consideration does not provide any insight into the behavior. (2) Mesoscale model is capable to realistically capture the thermal strain of non-loaded concrete as well as cement mortar without explicit definition of LITS in the thermo-mechanical model. (3) Using mesoscale modeling approach, the effect of compressive load on the thermal dilatation of concrete can be realistically captured using both aggregate-mortar models (concrete = mortar + coarse aggregates) as well as using aggregate-cement paste models (concrete = cement paste + aggregates). (4) Using the mesoscale models it is possible to realistically predict the cracking behavior of non-loaded and loaded concrete exposed to elevated temperature. (5) At lower temperatures, up to approximately $200^{\circ} \mathrm{C}$, the drying processes in cement paste are mainly responsible for the relaxation of the material, i.e. LITS. It is recognized that this temperature limit depends on the heating rate, give the kinematics of the drying processes, i.e. their time and heating rate dependency. (6) At temperatures beyond $200^{\circ} \mathrm{C}$ LITS primarily results from the interaction between thermally and load induced damage of mortar (cement paste) and ITZ. This damage changes the load transfer mechanism in concrete and at constant load leads to the increase of deformation with increasing temperature, i.e. the contribution of cement paste to the deformation becomes dominant. (7) In order to perform realistic analysis at mesoscale it is necessary to consider the realistic volumetric ratio of the concrete aggregates and the respective free thermal strain. This is especially important since simplified numerical models with only coarse aggregates (vol. ratio of up to $20-30 \%$ ) are generally preferred to detailed mesoscale models covering the complete range of the aggregate sizes (vol. ratio of 65- 
$80 \%$ ). (8) Further research is required for the increased heating rates, preferably those corresponding to real fire scenarios. Given the specific time dependency of the drying processes, the high pore pressures related to high heating rates and the influence of high thermally induced stresses on the concrete damage, it is essential to understand the combined action of these parameters on stress relaxation and LITS.

\section{REFERENCES}

[1] Hager, I. 2004. Comportement à haute température des bétons à haute performance -évolution des principales propriétés mécaniques, Ecole Polytechnique. PhD Thesis (in french).

[2] Anderberg, Y. Thelandersson, S. 1976. Stress and deformation characteristics of concrete at high temperatures, Report, Lund Institute of Technology. Division of Structural Mechanics and Concrete Construction.

[3] Khoury, G. 2006. Strain of heated concrete during two thermal cycles. Part 1: strain over two cycles, during first heating and at subsequent constant temperature. Magazine of Concrete Research 58(6): 367-385.

[4] Khoury, G., Grainger, B., Sullivan, P. 1985. Strain of concrete during first heating to $600 \mathrm{C}$ under load. Magazine of Concrete Research 37(133): 195-215.

[5] Khoury, G. 1995. Strain components of nuclear-reactor-type concretes during first heat cycle. Nuclear Engineering and Design 156(1): 313-321.

[6] Mindeguia, J.-C., Hager, I., Pimienta, P., Carré, H., La Borderie, C. 2013Parametrical study of transient thermal strain of ordinary and high performance concrete. Cement and Concrete Research 48: 40-52.

[7] Huismann, S. 2010. Materialverhalten von hochfestem Beton unter thermomechanischer Beanspruchung, Beuth Verlag, $\mathrm{PhD}$ Thesis (in german).
[8] Sabeur, H. and Meftah, F. 2008. Dehydration creep of concrete at high temperatures. Materials and Structures 41(1): 1730 .

[9] Bazant, Z. and Chern, J. 1987. Stressinduced thermal and shrinkage strains in concrete. Journal of Engineering Mechanics 113(10): 1493-1511.

[10] Nielsen, C., Pearce, C., Bicanic, N. 2002. Theoretical model of high temperature effects on uniaxial concrete member under elastic restraint. Magazine of Concrete Research 54(4): 239-249.

[11] Gawin, D., Pesavento, F., Schrefler, B. 2004. Modelling of deformations of high strength concrete at elevated temperatures. Materials and Structures 37(4): 218-236.

[12] Thelandersson, S. 1983. On the multiaxial behaviour of concrete exposed to high temperature. Nuclear engineering and design 75(2): 271-282.

[13] Ozbolt, J., Mayer, U., Vocke, H., Eligehausen, R. 1998. Das FE-Programm MASA in Theorie und Anwendung, Report, Institute for construction materials, University of Stuttgart. (in german)

[14] Pearce, C., Nielsen, C., Bicanic, N. 2004. Gradient enhanced thermo-mechanical damage model for concrete at high temperatures including transient thermal creep. International Journal for Numerical and Analytical Methods in Geomechanics 28(7-8): 715-735.

[15] Eurocode-2. 2004. Design of concrete structures, Part 1-2: General rules Structural fire design. European Committee for Standardization.

[16] Willam, K., Rhee, I., Xi, Y., "Thermal Degradation of Heterogeneous Concrete Materials," Journal of Materials in Civil Engineering 17(3), 276-285 (2005).

[17] Grondin, F. D. H., Hamida, A., Mounajed, G., Boussa, H. 2007. Multi-scales modelling for the behaviour of damaged concrete. Cement and Concrete Research 37(10): 1453-1462.

[18] Mounajed, G., Boussa, H., Grondin, F., Menou, A. 2005. Micro structural origin of the apparent thermal transient creep of concrete at high temperature. In Proceed- 
ings of 11th International conference on fracture ICF11; pp. 3131-3136.

[19] Grassl, P. and Pearce, C. 2010. Mesoscale approach to modeling concrete subjected to thermomechanical loading. Journal of engineering mechanics ASCE 136(3): 322-328.

[20] Ozbolt, J., Kozar, I., Eligehausen, R., Periskic, G. 2005. Instationäres 3D Thermo-mechanisches Modell für Beton. Beton- und Stahlbetonbau 100(1): 39-51. (in german).

[21] Periskic, G. 2009. Entwicklung eines 3D thermo-hygro-mechanischen Modells für Beton unter Brandbeanspruchung und Anwendung auf Befestigungen unter Zuglasten, University Stuttgart. $\mathrm{PhD}$ Thesis (in german).

[22] Ozbolt, J. and Bosnjak, J. 2011. Numerical simulation of the effect of high temperature on flexural and splitting strength of plain concrete. In Transactions SMiRT 21, Div-II: Paper ID 572.

[23] Ozbolt, J., Bosnjak, J., Periskic, G., Sharma, A. 2014. 3D numerical analysis of reinforced concrete beams exposed to elevated temperature. Engineering Structures 58: 166-174.

[24] Sharma, A., Bosnjak, J., Ozbolt, J., Hofmann, J. 2016. Numerical modeling of reinforcement pull-out and cover splitting in fire-exposed beam-end specimens. Engineering Structures 111: 217-232.

[25] Bazant, Z. and Oh, B. 1983. Crack band theory for fracture of concrete. Matériaux et Construction 16(3): 155-177.

[26] Ozbolt, J., Li, Y., Kozar, I. 2001. Microplane model for concrete with relaxed kinematic constraint. International Journaly of Solids and Structures 38(16): 2683-2711.

[27] Schneider, U. 1982. Verhalten von Beton bei hohen Temperaturen, Deutscher Ausschuss für Stahlbeton, Ernst \& Sohn.

[28] Nielsen, C. and Bicanic, N. 2003. Residual fracture energy of highperformance and normal concrete subject to high temperatures. Materials and Structures 36(8): 515-521.
[29] Cruz, C. and Gillen, M. 1980. Thermal expansion of Portland cement paste, mortar and concrete at high temperatures. Fire and Materials 4(2): 66-70. 